\title{
Functional Outcome of Total Hip Arthroplasty in Teenagers with End Stage Avascular Necrosis of the Head of Femur Resulting from Sickle Cell Disease
}

\author{
Alabi IA*, Salihu MN, Arojuraye SA, Okoh N, Arafat S, Bunu B, Aminu I, Siyaka AO \\ and Muhammad $A M$
}

National Orthopaedic Hospital, Nigeria

\begin{abstract}
Background: Sickle cell disease (SCD) is the commonest cause of avascular necrosis (AVN) among teenagers in our environment. When diagnosed early, joint preserving operations and physical therapy may prolong the congruency of the hip joint. However, due to the sociocultural behavior and the disequilibrium in universal health system in our sub region, the affected population often gets to the orthopaedic surgeons with advanced stage of the pathology affecting activities of daily living and carrier progression. This makes total hip arthroplasty (THA) inevitable. We looked at the functional outcome of THA in teenagers with advanced AVN secondary to SCD.

Methodology: Hospital-based, prospective, non-randomized study carried out at National Orthopaedic Hospital, Dala, Kano and Habeeby Orthopaedic Clinic, Kabuga, Kano, between $15^{\text {th }}$ of May 2015 and $14^{\text {th }}$ of May 2021. All patients aged 12 years to 19 years with stage IV Ficat and Arlet AVN whose parents consented for THA were included. Harris Hip Scoring (HHS) and Oxford Hip Scoring (OHS) were done for all patients on both hips pre-operatively and post-operatively at 1.5, 3, 6, 12 and 24 months. Uncemented THA was done using direct lateral approach. All patients were followed up for a minimum of 2 years. Data was analyzed using SPSS version 23 for windows.

Results: Thirty-eight hips in 27 patients were analyzed. The mean age was $16.8+/-2.0$ years with a F: M ratio of 2.5:1. All were haemoglobin ( $\mathrm{Hb})$ SS patients. The average pre-operative HHS and OHS of $27.7+/-6.6$ and $10.0+/-4.9$ respectively improved significantly to $93.0+/-2.2$ and $52.8+/-2.7$ respectively with $p$ value $<0.0001$ at 2 years. The mean $\mathrm{Hb}$ concentration preoperatively was $8.6 \mathrm{~g} / \mathrm{dl}+/-0.6 \mathrm{~g} / \mathrm{dl}$. No patient was transfused pre-operatively, but all had 1,2 or 3 pints of blood transfused postoperatively. Two patients had superficial surgical site infection that resolved with antibiotics and wound dressing. A patient had limb length discrepancy of more than $2 \mathrm{~cm}$ that necessitated revision a week after the first surgery. Three patients had Uncemented stem revised to cemented stems at 2 years to 3 years postoperatively due to aseptic loosening. All the patients were alive throughout the course of the study.
\end{abstract}

Conclusion: Total hip arthroplasty in teenagers with AVN from sickle cell disease is safe and rewarding, though challenging. It gives excellent functional outcome with minimal complications.

\section{Keywords}

Teenagers, Avascular necrosis of the head of femur and sickle cell disease

\section{Introduction}

Debilitating arthritis in teenage patients is a complex problem with limited surgical options [1]. Avascular necrosis (AVN) especially of the femoral head has long been recognized as a morbidity of sickle cell disease (SCD) [2]. Avascular necrosis of bone is a frequent and severe complication of sickle cell disease, and its treatment is not standardized [3]. SCD is the most common cause of osteonecrosis of the femoral head (ONFH) during childhood with an overall prevalence of $10 \%$ [4]. The physiopathology reflects an alteration of the vascularization of the fine blood vessels irrigating the anterior and superior part of the femoral head [5]. Necrosis within the femoral head may cause severe pain, functional limitations, and compromise quality of life in this patient population [6]. Majority of patients had an advanced disease at diagnosis2. Presentation is often with secondary osteoarthritis in our environment.

*Corresponding author: Ibrahim Abolaji Alabi, Department of Clinical Services, National Orthopaedic Hospital, PMB 3087, Dala-Kano, Nigeria, Tel: +2348059200014; +2348035217883

Accepted: August 16, 2021

Published online: August 18, 2021

Citation: Alabi IA, Salihu MN, Arojuraye SA, et al. (2021) Functional Outcome of Total Hip Arthroplasty in Teenagers with End Stage Avascular Necrosis of the Head of Femur Resulting from Sickle Cell Disease. J Orthop Rheumatism 5(1):93-97 
Citation: Alabi IA, Salihu MN, Arojuraye SA, et al. (2021) Functional Outcome of Total Hip Arthroplasty in Teenagers with End Stage Avascular Necrosis of the Head of Femur Resulting from Sickle Cell Disease. J Orthop Rheumatism 5(1):93-97

The precarious blood supply of the head and its role as a major weight-bearing joint makes it one of the most common bones to be affected by osteonecrosis [7]. Osteonecrosis of the femoral head is a common complication in patients with sickle cell disease, and collapse of the femoral head occurs in $90 \%$ of patients within five years after the diagnosis of the osteonecrosis [8], majority of whom are in their second to third decades [9]. Femoral head avascular necrosis leads to osteoarthritis of the hip joint and affects its functional capacity in sickle cell disease patients [10]. Early stages of avascular necrosis of the hip may be managed surgically with core decompression with or without autologous bone grafting [6]. Though Martí-Carvajal AJ, Solà I and Agreda-Pérez LH found no evidence that adding hip core decompression to physical therapy achieves clinical improvement in people with sickle cell disease with avascular necrosis of bone compared to physical therapy alone [3].

Sickle cell disease is an autosomal recessive, multisystem disorder, characterized by chronic haemolytic anaemia, painful episodes of vaso-occlusion, progressive organ failure and a reduced life expectancy [11]. In well-resourced countries, comprehensive care programs have increased life expectancy of sickle cell disease patients, with almost all infants surviving into adulthood [11]. Early diagnosis is challenging as the onset of disease is insidious and the symptoms and signs are usually minimal and nonspecific until it becomes advanced [12]. Peak age for operations was 1620 years [13]. The young age of patients, total arthroplasties complications risks, and implant costs justify evaluation of the results of core decompression in the treatment of sickle-cell disease avascular necrosis of the femoral head [14]. However, the stage of the disease at presentation in our environment makes core decompression and other joint preserving procedures inconceivable. Patients present with advanced stage in our environment as early as 12 years of age. Functional limitations with or without deformities from these complications of sickle cell disease often require Total Hip Arthroplasty (THA) to improve outcome [15].

Other authorities have advocated hip arthrodesis, but a major Muslim community will not trade their normal praying posture of bending the hip for anything else. Although there is an increased risk of medical and surgical complications in patients with sickle cell disease, total hip arthroplasty can provide substantial relief of pain and improvement of function in the appropriately selected patient $[6,16]$. Once femoral head collapses (> $2 \mathrm{~mm}$ ) or if there is secondary degeneration, hip conservation procedures become ineffective, and arthroplasty remains the only better option [17]. In general, femoral head spearing procedure (FHSP) are indicated at pre-collapse stages with minimal symptoms whereas femoral head replacement procedures (FHRP) are preferred at post-collapse symptomatic stages [18]. Total hip arthroplasty is the mainstay of treatment of advanced stages of the disease in patients who have intractable pain and are medically fit to undergo the procedure [6]. Thus, the need to do it even in teenagers.

\section{Methodology}

Hospital-based, prospective, non-randomized study carried out at National Orthopaedic Hospital, Dala, Kano and Habeeby Orthopaedic Clinic, Kabuga, Kano, between $15^{\text {th }}$ of May 2015 and $14^{\text {th }}$ of May 2021. All patients aged 12 years to 19 years with stage IV Ficat and Arlet AVN whose parents consented for THA were included [a typical advanced AVN is
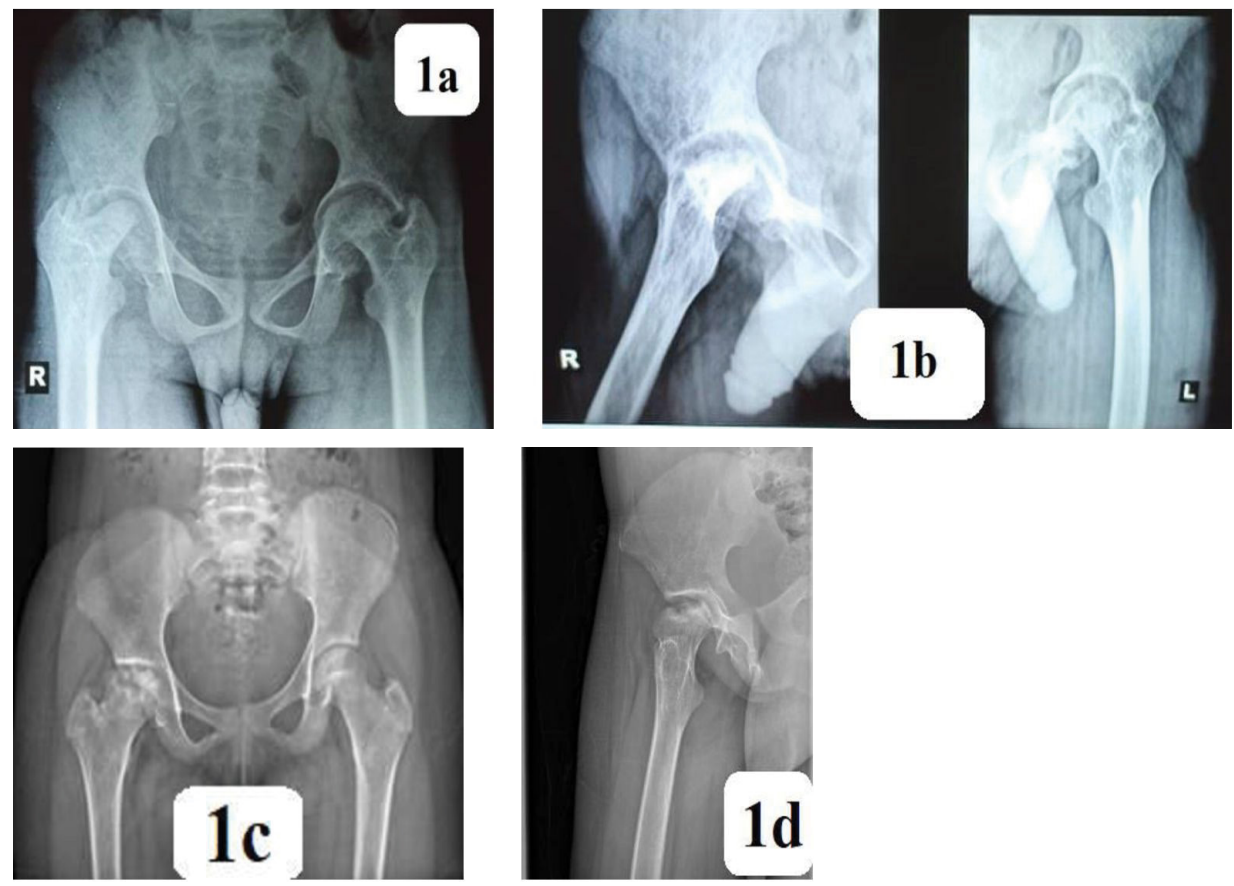

Figure 1: A,B) Shows pre-operative radiographs of a 17-year-old SCD teenager with stage IV Ficat and Arlet AVN. It showed bilateral AVN with a collapsed and resolved heads more on the right with secondary osteoarthritis. C,D) Showed the pelvis of a 14-year-old SCD girl with unilateral collapsed head and secondary arthritic changes. 
Citation: Alabi IA, Salihu MN, Arojuraye SA, et al. (2021) Functional Outcome of Total Hip Arthroplasty in Teenagers with End Stage Avascular Necrosis of the Head of Femur Resulting from Sickle Cell Disease. J Orthop Rheumatism 5(1):93-97

shown in Case 2 (Figure $1 \mathrm{~A}$ and Figure 1B) and Case 2 (Figure 1C and Figure 1D)]. Harris Hip Scoring (HHS) and Oxford Hip Scoring (OHS) were done for all patients on both hips preoperatively and post-operatively at 1.5, 3, 6, 12 1st 24 months. Genotypes were determined or re-affirmed. Bilaterality was considered and recorded. Previous care was noted. Preoperative $\mathrm{Hb}$ was determined and correlated to the patients' steady state. Uncemented THA was done using direct lateral approach. Subperiosteal detachments of the iliopsoas muscle and adductor tenotomy were done when indicated. Sizes of prostheses used, and company were noted. Weight-bearing ambulation was commenced on the second postoperative day. Perioperative events and complications were noted and recorded. Data was analyzed using SPSS version 23 for windows.

\section{Results}

Thirty-eight hips in 27 patients were analyzed. The mean age was $16.8+/-2.0$ years with a F:M ratio of 2.5:1. Average duration of symptoms was $3.3+/-1.4$ years. All were haemoglobin $(\mathrm{Hb})$ SS patients. Seventy-nine percent of the patients were students (Figure 2). Average weight was 49.2 +/- $5.9 \mathrm{Kg}$, mean height was $1.58+/-0.06 \mathrm{~m}$ and the mean Body Mass Index (BMI) was $19.58+/-1.0 \mathrm{Kg} / \mathrm{m}^{2}$. Mean $\mathrm{Hb}$ concentration preoperatively was $8.6+/-0.6 \mathrm{~g} / \mathrm{dl}$. No patient was transfused pre-operatively. The average pre-operative HHS and OHS were $27.7+/-6.6$ and $10.0+/-4.9$ respectively. All had regional anaesthesia (spinal or epidural). The mean operation time was 116.9 +/- 34.7 minutes (range 80-185 minutes). The implants used were mainly from Depuy, Surgival and Zimmers, all were metal head on polyethylene acetabular linner (the commonly available in our environment). The average acetabular shell size used was 46.9 +/- $2.4 \mathrm{~mm}$ (range $44 \mathrm{~mm}$ to $54 \mathrm{~mm}$ ). The smallest stems in all the systems were used commonly.

The average estimated blood loss (EBL) was 686.8 +/169.1 (range $400 \mathrm{ml}-1000 \mathrm{ml}$ ). Eighteen patients received 2 pints of blood, while 14 got 3 pints of blood. Ten of those that received 3 pints of blood had bilateral THA. Post-operative radiographs were obtained first day post-operatively (Figure 3). Six patients

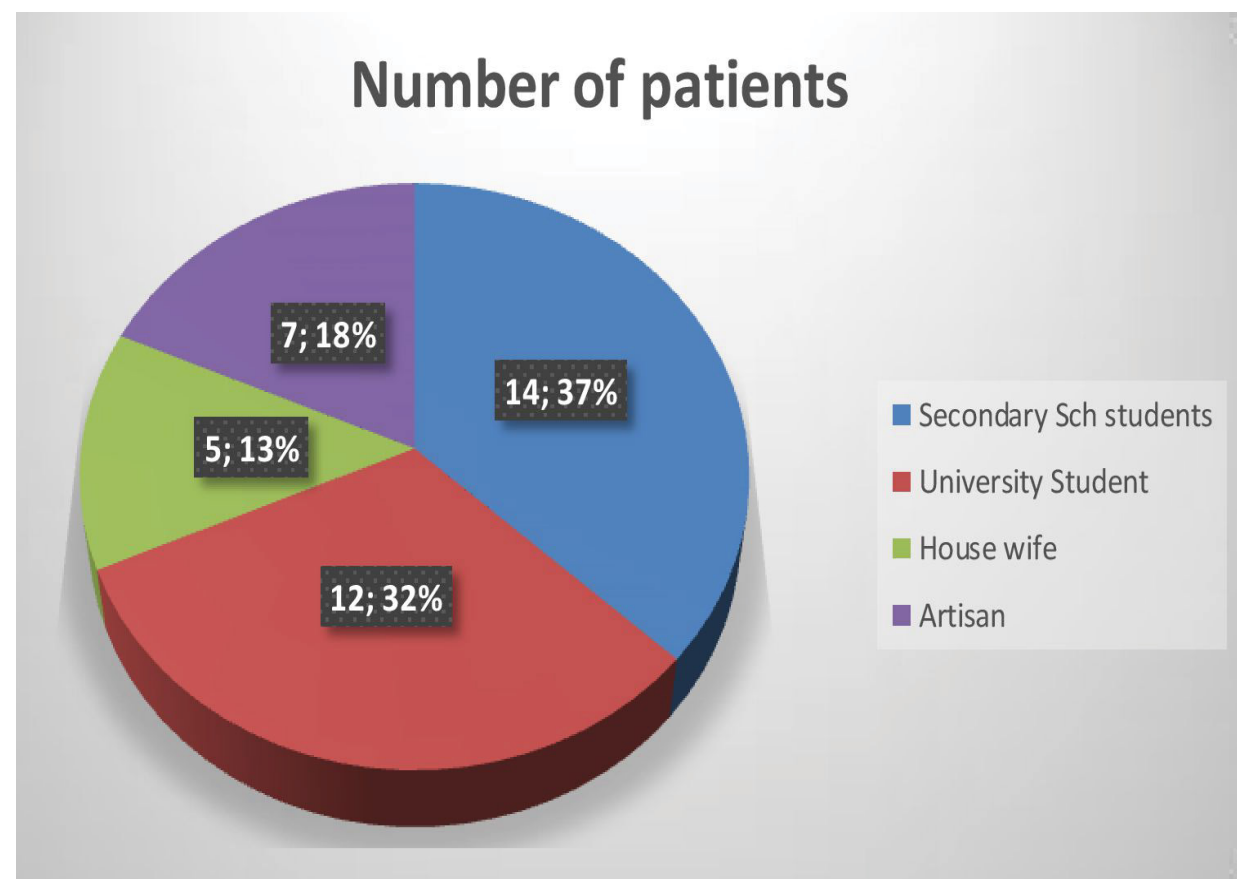

Figure 2: Showed occupational distribution of the teenagers treated for AVN from SCD.
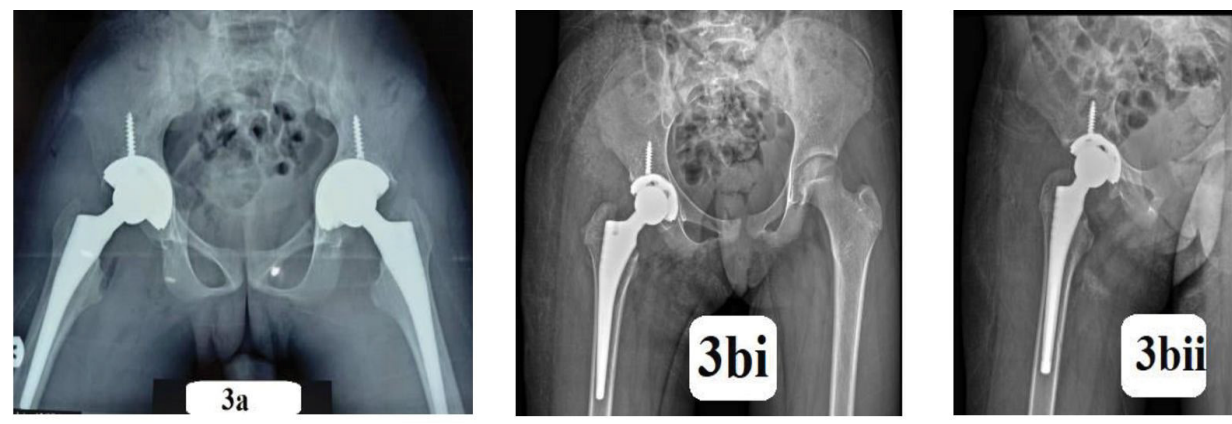

Figure 3: A) Shows postoperative radiograph for case 1 B) Post-op radiographs for Case 2 

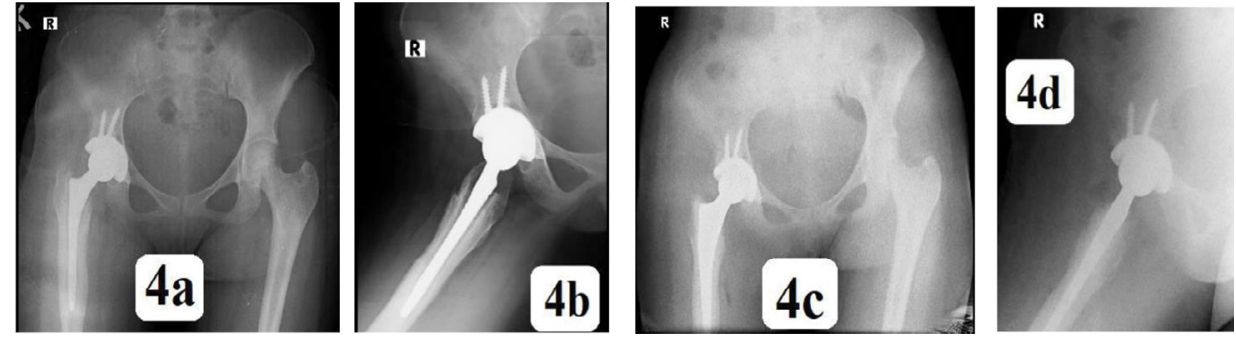

Figure 4: A,B) These show Ap and Lateral views of aseptic loosening before revision. C,D) Revision to cemented stem in Case 3.

received only 1 pint of blood each. The average hospital stay in this study was $8.9+/-2.9$ days (range 7 to 14 days). All patients ambulated weight-bearing at second postoperative day. The average post-operative HHS and OHS statistically and significantly improved to $93.0+/-2.2$ and $52.8+/-2.7$ respectively with $p$ value $<0.0001$ at 2 years.

All patients were followed up for a minimum of 2 years (range 2 years to 5 years). Two patients had intra-operative cracks in the proximal femur that required cerclage wiring. Three patients had Uncemented stem revised to cemented stems at 2 years to 3 years postoperatively due to aseptic loosening [Case 3, (Figure 4)]. None of the acetabular shells was revised. Two patients had superficial surgical site infection that resolved with antibiotics. Both of them had bilateral THA and the infections were acute and on the first operated hip. Two patients had limb length discrepancy (LLD) of more than $2 \mathrm{~cm}$ that necessitated revision a week after the first surgery. All the patients were alive throughout the course of the study.

\section{Discussion}

Despite advances in the treatment of paediatrichip disease, adolescent and young adult patients can develop early onset end-stage osteoarthritis [19]. In our environment, there is paucity of specialized SCD clinics and poor attendance where available. Teenagers with SCD often present with advanced stage of the disease. Arthrodesis that may be acceptable in the other part of the world is totally unacceptable in our region due to Islamic religious inclination. Hip arthrodesis is unpopular amongst patients, and contemporary total hip arthroplasty (THA) may be a promising alternative [1]. Patel NK, et al. reported good short to intermediate term survivorship and outcomes and feel that THA represents a valid alternative option to hip arthrodesis.1 Azam MQ and Sadat-Ali $\mathrm{M}$ also recommend early hip arthroplasty in sickle cell patients, if the hip has reached a stage of irreversible damage and patient's lifestyle is severely compromised to minimize chronic suffering and disability [9]. Katchy, et al. stated that detailed planned total hip arthroplasty can be performed in younger patients with SCD with good clinical benefits [20]. Thus, the need for us to look at the outcome of THA in teenagers prospectively.

Our study showed female preponderance in the ratio of 2.5: 1. Patel NK, et al., Ugbeye ME, et al. and Buddhdev PK and colleagues also recorded higher incidences in females than male $[1,15,19]$. This may not be unrelated with earlier puberty attainment in females characterized by earlier rapid growth and increased need for more blood supply which may be sub-optimal in patients with SCD. It may also be due to sociocultural value of showing more concern for females, their less ability to withstand stressful situations, and thus earlier presentation. Our environment is endemic for malaria disease. Coupled with paucity of specialized SCD clinic, most of the SCD patients are often in and out of the hospital with recurrent admission for acute chest syndrome and vasoocclusive crisis. This scenario makes SCD to be more severe among children in our locality. Adesina O, Brunson A, Keegan THM and Wun T reported that THA was higher among SCD patients with more severe disease (24\%; vs. $8 \%$ in less severe) and those with antecedent acute chest syndrome (ACS) (18\%; vs. $8 \%$ without prior history of ACS) [21].

A mean age of $16.8+/-2.0$ years was recorded in this study with a range of 12 years-19 years. This was similar to the findings of Patel NK, et al. where a mean age of 17 years was recorded with similar range. 1 in the study by Ugbeye, et al., no patient required adductor tenotomy [15]. This is contrary to our findings as there was a need for adductor tenotomy in 28 hips. This can be due late presentation in our environment where patients present with like significant limb length discrepancy (LLD), high-riding trochanters, pelvic obliquity, and significant limitation in all range of motions. There was statistically significant improvement in HHS and $\mathrm{OHS}$ with $\mathrm{p}$-value $<0.0001$. This is consistent with the findings of Azam MQ, Sadat-Ali M, Ugbeye ME, et al., Katchy, et al. and Salihu MN, et al. [9,15,22,23].

Yawn BP, et al. stated that in persons with sickle cell anemia, preoperative transfusion therapy to increase hemoglobin levels to $10 \mathrm{~g} / \mathrm{dl}$ is strongly recommended with a moderate strength recommendation to maintain sickle hemoglobin levels of less than $30 \%$ prior to the next transfusion during long-term transfusion therapy [24]. Jack $\mathrm{CM}$, et al. also reported 48 cases that had exchange blood transfusion preoperatively and 3 had top-up transfusions [23]. In our practice, it was observed that when SCD patients are transfused well above their steady $\mathrm{Hb}$ state, they suffer hemolysis back to their state. This increases their serum bilirubin level and worsens their jaundice which will subsequently increase the chances of periprosthetic joint infection and vaso-occlusive crisis postoperatively.

Al-Mousawi $F$, et al. reiterated the importance of patients and surgeons being aware of the wide varieties of complications [25]. Azam MQ, Sadat-Ali M reported revision 
Citation: Alabi IA, Salihu MN, Arojuraye SA, et al. (2021) Functional Outcome of Total Hip Arthroplasty in Teenagers with End Stage Avascular Necrosis of the Head of Femur Resulting from Sickle Cell Disease. J Orthop Rheumatism 5(1):93-97

surgery was required in 7 patients for aseptic loosening and in 1 patient due to late infection [9]. Three of the patients in this study had Uncemented stem revised to cemented on account of aseptic loosening (Figure 4). Adesina O, Brunson A, Keegan THM and Wun T reported that $27 \%$ of post-hip surgery patients were readmitted within 30 days, mostly for painful vaso-occlusive crises [21]. This was not the experience in this study. Jack CM, et al. reported that it was necessary to drill the femur during 12 hips [23]. Eighteen proximal femoral drillings were done to channel the femoral canals that were obliterated. Significant periprosthetic fractures were avoided, but two patients developed cracks that warranted cerclage wiring.

\section{Conflicts of Interest}

No conflicts of interest.

\section{References}

1. Patel NK, Luff T, Whittingham-Jones $P$, et al. (2012) Total hip arthroplasty in teenagers: An alternative to hip arthrodesis. HIP Int 22: 621-627.

2. Elalfy MS, Fadhli I, Mohammad S, et al. (2018) Avascular necrosis of the femoral head in sickle cell disease in Egypt and Oman: A cross sectional study. Blood 132: 4921.

3. Martí-Carvajal AJ, Solà I, Agreda-Pérez LH (2016) Treatment for avascular necrosis of bone in people with sickle cell disease. Cochrane Database Syst Rev.

4. Mallet C, Abitan A, Vidal C, et al. (2018) Management of osteonecrosis of the femoral head in children with sickle cell disease: Results of conservative and operative treatments at skeletal maturity. J Child Orthop 12: 47-54.

5. Petek D, Hannouche D, Suva D (2019) Osteonecrosis of the femoral head: Pathophysiology and current concepts of treatment. EFORT open Rev 4: 85-97

6. Kamath AF, McGraw MH, Israelite CL (2015) Surgical management of osteonecrosis of the femoral head in patients with sickle cell disease. World J Orthop 6: 776-782.

7. Baig SA, Baig MN (2018) Osteonecrosis of the femoral head: Etiology, investigations, and management. Cureus 10: e3171.

8. Neumayr LD, Aguilar C, Earles AN, et al. (2006) Physical therapy alone compared with core decompression and physical therapy for femoral head osteonecrosis in sickle cell disease: Results of a multicenter study at a mean of three years after treatment. J Bone Joint Surg Am 88: 2573-2582.

9. Azam MQ, Sadat-Ali M (2016) Quality of life in sickle cell patients after cementless total hip arthroplasty. J Arthroplasty 31: 25362541.

10. Al-Otaibi ML, Waliullah S, Kumar V (2021) Total hip replacement in sickle cell disease patients with avascular necrosis of head of femur: A retrospective observational study. Indian J Orthop 1-7.
11. Houwing ME, De Pagter PJ, Van Beers EJ, et al. (2019) Sickle cell disease: Clinical presentation and management of a global health challenge. Blood Rev 37: 100580.

12. Choi H-R, Steinberg ME, Y Cheng E (2015) Osteonecrosis of the femoral head: diagnosis and classification systems. Curr Rev Musculoskelet Med 8: 210-220.

13. Region O, Ayana B, Ahmed E (2020) Management of avascular necrosis of femoral head (ANFH) in sickle cell disease. East Cent African J Surg 17: 37-42.

14. Mukisi-Mukaza M, Manicom O, Alexis C, et al. (2009) Treatment of Sickle cell disease's hip necrosis by core decompression: A prospective case-control study. Orthop Traumatol Surg Res 95: 498-504.

15. Ugbeye ME, Lawal W, Ayodabo O, et al. (2020) Total hip arthroplasty in sickle cell disease patients in a developing country. Niger J Clin Pract 23: 1426-1430.

16. Hernigou P, Zilber S, Filippini $P$, et al. (2008) Total THA in adult osteonecrosis related to sickle cell disease. Clin Orthop Relat Res 466: 300-308.

17. Tripathy SK, Goyal T, Sen RK (2015) Management of femoral head osteonecrosis: Current concepts. Indian J Orthop 49: 2845 .

18. Moya-Angeler J, Gianakos AL, Villa JC, (2015) Current concepts on osteonecrosis of the femoral head. World J Orthop 6: 590601.

19. Buddhdev PK, Vanhegan IS, Khan T, et al. (2020) Early to medium-term outcomes of uncemented ceramic-bearing total hip arthroplasty in teenagers for paediatric hip conditions. Bone Jt J 102: 1491-1496.

20. Katchy A, Anyaehie U, Nwadinigwe C, et al. (2018) Total hip replacement in sickle cell disorder: A preliminary report of challenges and early outcome of 21 consecutive patients. Niger J Clin Pract 21: 492-495.

21. Adesina O, Brunson A, Keegan THM, et al. (2017) Osteonecrosis of the femoral head in sickle cell disease: Prevalence, comorbidities, and surgical outcomes in california. Blood Adv 1: 1287-1295.

22. Suksathien $Y$, Sueajui J (2019) Mid-term results of short stem total hip arthroplasty in patients with osteonecrosis of the femoral head. HIP Int 29: 603-608.

23. Jack CM, Howard J, Aziz ES, et al. (2016) Cementless total hip replacements in sickle cell disease. HIP Int 26: 186-192.

24. Yawn BP, Buchanan GR, Afenyi-Annan AN, et al. (2014) Management of sickle cell disease: Summary of the 2014 evidence-based report by expert panel members. JAMA 312: 1033-1048.

25. Al-Mousawi F, Malki A, Al-Aradi A, et al. (2002) Total hip replacement in sickle cell disease. Int Orthop 26: 157-161.

DOI: $10.36959 / 479 / 439$

Copyright: (C) 2021 Alabi IA, et al. This is an open-access article distributed under the terms of the Creative Commons Attribution License, which permits unrestricted use, distribution, and reproduction in any medium, provided the original author and source are credited. 